\title{
Research on the Realization Path of Social Commerce Consumption Poverty Alleviation Mode
}

\author{
Xiaolin $\mathrm{Li}^{1,}{ }^{*}$, Jiali Cai ${ }^{1}$, Yunzhong $\mathrm{Cao}^{2}$, Liangqiang $\mathrm{Li}^{1}$ \\ ${ }^{1}$ Business School, Sichuan Agricultural University, Chengdu, China \\ ${ }^{2}$ College of Architecture and Urban-Rural Planning, Sichuan Agricultural University, Chengdu, China
}

Keywords: Rural revitalization; Targeted poverty alleviation; Social commerce; Consumption poverty alleviation; Realization path

\begin{abstract}
In the context of the rural revitalization strategy, targeted poverty alleviation is essential and has become a research upsurge among scholars at home and abroad. What kind of poverty alleviation mode and how to effectively realize poverty alleviation in poor areas is the research focus of targeted poverty alleviation. With the development and reform of Internet and e-commerce, the poverty alleviation mode is constantly explored and innovated. However, most of the previous studies focused on the traditional e-commerce mode of poverty alleviation, and few studied on the social commerce consumption poverty alleviation mode. Therefore, combining the present situation of poverty alleviation, this research explores the realization path of social commerce consumption poverty alleviation mode, and studies how the economic development of poverty-stricken areas can be effectively driven under the poverty alleviation mode, so as to realize the rural revitalization. Finally, the conclusion is drawn that the social commerce consumption poverty alleviation mode has a significant effect on promoting targeted poverty alleviation. This study provides a useful reference for the work of poverty alleviation in the context of rural revitalization strategy, and provides feasible suggestions for relevant departments.
\end{abstract}

\section{Introduction}

In 2017, China established the rural revitalization strategy. In this context, the research on targeted poverty alleviation is particularly important. Get rid of poverty is the key to rural revitalization, among them, poverty alleviation through consumption is a long-term, effective and sustainable poverty alleviation mechanism. Simultaneously, as the Internet penetrates the countryside, e-commerce is on the rise and is closely integrated with poverty alleviation, which has greatly promoted farmers to shake off poverty and become a mainstream means of poverty alleviation with a new mode different from the traditional industrial poverty alleviation. Today, the flow dividend is gradually disappearing, and the traditional e-commerce has been unable to meet consumer demand. In its place is new e-commerce, namely social commerce. In the face of China's emphasis on ensuring that by 2020 China will achieve the target task of out of poverty for the rural poor and building a moderately prosperous society in an all-round way, 2019 has become a decisive period for poverty alleviation. However, the present situation of poverty in many areas of China is still serious. The task of poverty alleviation is arduous. Therefore, this paper argues that it is necessary to use the new social commerce consumption poverty alleviation mode to help alleviate poverty.

\section{Literature Review}

\subsection{Poverty alleviation by e-commerce}

E-commerce poverty alleviation is a new way of poverty alleviation that can help farmers cast off poverty to get rich by connecting the market and the production area through e-commerce, that is, to integrate e-commerce into the poverty alleviation and development work system, to expand sales channels for poor farmers through e-commerce platform, and to promote sales of agricultural 
products of poor farmers [1].

Domestic and foreign scholars' studies on e-commerce poverty alleviation primarily concentrated in development, application, mechanism of action of e-commerce poverty alleviation in poor areas, and exploration and innovation of the e-commerce poverty alleviation mode. For example, Lei et al. (2019) [2] studied the development and application of e-commerce poverty alleviation in the poor rural areas of Xinjiang, and put forward corresponding countermeasures and suggestions for problems such as poor adaptability, imperfect mechanism and lack of cognition of farmers in the application of e-commerce poverty alleviation, in order to promote the effective combination of rural e-commerce and targeted poverty alleviation in poor areas of Xinjiang, and then realize accelerated poverty alleviation. Song et al. (2018) [3] used SWOT analysis theory to further optimize the design of rural e-commerce poverty alleviation in Southeast Chongqing, to promote the long-term development of rural e-commerce poverty alleviation and maximize its effectiveness. Li et al. (2019) [4] studied the influence of developing rural e-commerce ecosystem on poverty reduction in longnan county, based on activity theory analysis method, the study showed that ecommerce ecosystem has a significant effect on poverty reduction in poor areas. Tang et al. (2019) [5] found that key role of the e-commerce poverty alleviation mode led by different poverty alleviation subjects is different, and proposed that: distressed areas should comprehensively consider the characteristics of different poverty alleviation modes, lay stress on the differences of poverty alleviation subjects, and select the most suitable e-commerce poverty alleviation mode for their own development according to their actual needs. Wang et al. (2017) [6] practice analyzed whether the mode of "financial service station + Internet + rural e-commerce" can drive the development of special industries in Yanling County, Hunan Province, so as to promote farmers to get rid of poverty. The results showed that this mode was feasible. Another example is Guo et al. (2019) [7] aiming at a series of e-commerce poverty alleviation implementation plans put forward by Longnan City, Gansu Province, under the background of the national poverty alleviation war, gradually explored the "Longnan mode" suitable for local e-commerce poverty alleviation.

To sum up, e-commerce poverty alleviation is an important measure in the current poverty alleviation work. E-commerce poverty alleviation can greatly promote the economic development of poor areas, accelerate poverty alleviation in poor areas, so as to speed up the fight to win the poverty alleviation battle, and then help to realize rural revitalization. However, in the process of ecommerce poverty alleviation, there will still be problems of poor poverty alleviation effect. Therefore, it is necessary to explore and innovate the e-commerce poverty alleviation mode to help the poor more effectively.

\subsection{Research on social e-commerce development}

Social e-commerce combines social and business, which mainly utilizes Internet social tools and based on the social relations of users to interact and spread to achieve business transactions [8].

In recent years, the number of netizens has increased dramatically, social-based relationship networks have been rapidly established and developed, social e-commerce comes into being, which has caused a certain impact on traditional e-commerce. For example, Huang (2018) [9] took Pinduoduo and Taobao as examples to conduct a comparative study on the development status of social e-commerce and traditional e-commerce, the analysis showed that traditional e-commerce has gradually become weak, in urgent need of innovation and social transformation. Domestic and foreign scholars' studies on social e-commerce focus on its development and mode. For example, Gibreel et al. (2018) [10] explored the development of social commerce in emerging markets from three interconnected aspects of society, technology and social technology. Ma (2018) [11] believed that under the trend of gradually declining flow dividends, social networks provide a huge development space for e-commerce with its unique social properties such as interaction and extensive participation. The integration of social network and e-commerce is the mainstream trend and has a bright future. Based on the huge development space of social e-commerce, Jia (2017) [12] discussed and analyzed the current development mode and market prospect of social e-commerce under the "Internet +" trend. Lin (2018) [13] took the typical social e-commerce platform "Mogujie" 
and "Meilishuo" as an example, systematically analyzed the profit dilemma existing in the development of "Mogujie" and "Meilishuo" when the new business mode of social e-commerce started to rise but was not mature, and proposed the improvement measures to find new economic growth points of the platform to improve the market competitiveness, so as to promote the optimization of the mode and further promote enterprises's development.

To sum up, under the background that e-commerce has gradually replaced the traditional industrial poverty alleviation with its own platform advantages and become an effective mode of targeted poverty alleviation, the rapid rise of social e-commerce in recent years has further expanded channels of e-commerce poverty alleviation. Social e-commerce began to be combined with poverty alleviation, and a new type of e-commerce poverty alleviation mode -- social ecommerce targeted poverty alleviation emerged, namely through social interaction to communicate and spread, to achieve direct communication between consumers and producers, so as to better promote sales of agricultural products, and then drive the economic development in poor areas and finally get out of poverty. Social e-commerce poverty alleviation has gradually become an emerging trend of poverty alleviation today, but its mode development is not mature and needs continuous improvement.

\subsection{Research on the development of consumption poverty alleviation}

In recent years' exploration, consumption poverty alleviation has gradually become a new measure to fight the battle against poverty. Consumption poverty alleviation means that online or offline consumers purchase characteristic agricultural products or services in impoverished areas by way of consumption, and use consumption to drive development to promote poverty alleviation and increase income for poor households.

With regard to consumption poverty alleviation, scholars have focused on their research on assisting the development of targeted poverty alleviation. For example, Chen (2019) [14] thought that poverty alleviation through consumption is essentially a kind of buying and selling behavior to achieve the purpose of poverty alleviation through trade, and advocated that consumers should strongly support poverty alleviation through consumption to promote the implementation effect of consumption poverty alleviation and help to achieve victory in the fight against poverty. Sun et al. (2017) [15] believed that although China has made great achievements in combating poverty, poverty caused by insufficient consumption still exists, and consumption poverty is particularly significant in remote rural areas. It was an important way to reduce poverty by introducing consumption poverty alleviation, objectively and scientifically analyzing how to promote consumption in poverty-stricken areas and then promote local economic development. Chen (2019) [16] believed that it was the innovative direction of targeted poverty alleviation to carry out in-depth consumption poverty alleviation and help win the battle of poverty alleviation. Some scholars also put forward deeper suggestions for the development of consumption poverty alleviation. For example, Ge (2019) [17] proposed that the "five in one" one-stop consumption poverty alleviation e-commerce platform should be established to promote the deep integration of poverty alleviation and consumption.

In conclusion, the application of consumption poverty alleviation in targeted poverty alleviation has been unanimously recognized by scholars, who believe that more efforts should be made to promote the development process of consumption poverty alleviation. The core of consumption poverty alleviation lies in the full connection between demand and supply, that is, the scattered poverty-stricken areas and the huge consumer groups will be connected with each other, the consumer demand of consumers will be integrated with the resources of poverty-stricken areas to form a large-scale "supply-demand" matching, and the "one-stop" consumption poverty alleviation from goods to services will be realized through the online and offline integrated business mode. After several explorations and studies, the development process of poverty alleviation by consumption has accelerated significantly, showing a new trend of wider scope and greater impact. 


\section{Research on the New Mode of Social Commerce Consumption Poverty Alleviation and Its Realization Path}

With the continuous development of the Internet, information and traffic are gradually becoming fragmented and decentralized. A new product in the post-e-commerce era, social commerce, has gradually emerged and has become a new outlet in recent years. Domestic scholars' studies generally tend to split social commerce into a "social intercourse + e-commerce" mode, that is, integrating e-commerce on social platforms, usually researching e-commerce development modes based on social media. For example, Yang et al. (2018) [18] studied how social commerce with WeChat as a medium builds a WeChat ecosystem to innovate and apply the social commerce mode. However, as an effective measure of poverty alleviation in recent years, there are few researches on the combination of consumption poverty alleviation and social commerce. In contrast, the development of social commerce started earlier, and the maturity of development was higher abroad. Foreign scholars also have more research results. The rise of China's social commerce is also inspired by the American Pinterest website. Foreign scholars mainly study the development mode of social commerce, especially take the current popular social commerce platform as the research object. For example, Mamonov et al. (2017) [19] used Facebook gifts as research objects to innovate social networking sites, and explored the factors affecting the adoption of social commerce services, and then explored the social commerce innovation development mode. Similarly, there are few literature studies on the combination of social commerce and consumption poverty alleviation in foreign countries. Therefore, this article intends to explore the combination of the two to help poverty alleviation work, and then innovatively proposes a new mode of social commerce consumption poverty alleviation.

As a new business format emerging today, social commerce, it can build a bridge between consumers and producers through human-to-human communication and dissemination, providing a wider space for online sales of agricultural products and bringing more convenient services. In May 2018, China launched an attempt of social e-commerce to help consumption poverty alleviation at the China consumption poverty alleviation Summit Forum, namely the "warm China, social ecommerce consumption poverty alleviation action" sponsored by the social e-commerce special committee of China E-Commerce Association, which has achieved certain results in increasing incomes of poor households and lifting them out of poverty so far. The present situation of poverty alleviation at this time: at the end of 2018, there was a significant reduction in poverty, and the battle against poverty had achieved remarkable results, but the task of lifting people out of poverty in 2019 was still arduous. In the context of rural revitalization, targeted poverty alleviation is the key and the focus of the government's work. Under the implementation of the government's poverty alleviation policy, the new development mode of social commerce consumption poverty alleviation will be spread out in an all-round way, continuously be innovated and tapped, and has a good development prospect.

Based on the above analysis, this paper constructs an implementation path diagram of the social commerce consumption poverty alleviation mode to further illustrate application and development of the new mode and its mechanism of action, and then explores whether the new mode can effectively help the poor. As shown in Figure 1.

In order to further accelerate the development of poverty-stricken areas, help poor areas to get rid of poverty, national government departments have formulated a series of policies, institutional mechanisms and provide funds to give strong support to the work of poverty alleviation. The social commerce consumption poverty alleviation mode proposed in this paper refers to promoting the connection between poor areas and the market through the social commerce platform, broadening sales channels of agricultural products in poor areas, promoting the sale of agricultural products, and driving economic development with consumption, thereby helping poverty reduction. In order to specifically illustrate the path of the new mode of poverty alleviation and its effect, this article takes the social commerce platform Pinduoduo as an example, analyzes and studies the case of Pinduoduo consumption poverty alleviation, and innovatively proposes to integrate 5G technology 
to better improve the new poverty alleviation mode, promote the progress of poverty alleviation work, and then help achieve rural revitalization .

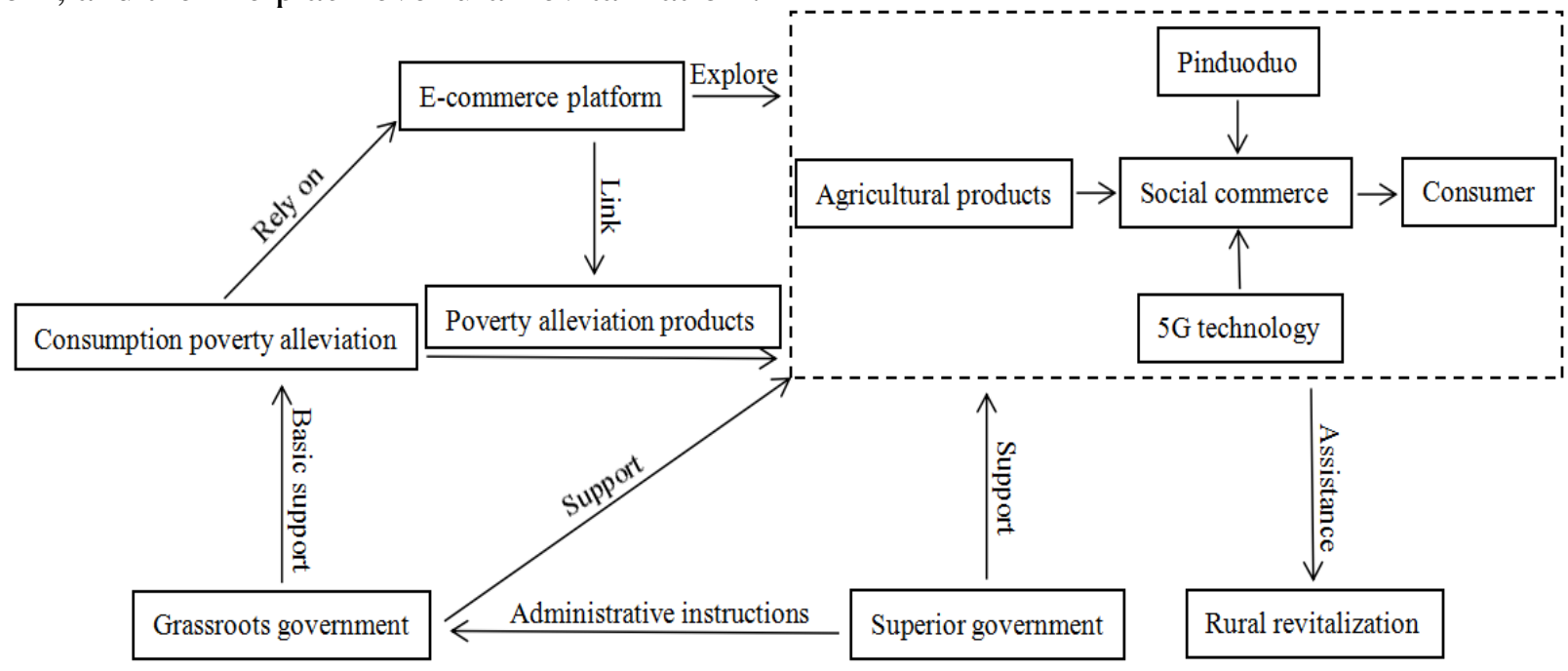

Figure 1 Realization path of social commerce consumption poverty alleviation mode.

In recent years, Pinduoduo, the biggest black horse in the e-commerce industry, has become one of the three e-commerce giants with its unique group shopping mode, which is now widely known. Under the situation that the flow dividend is exhausted and the e-commerce is in the dilemma of weak growth, Pinduoduo has developed rapidly in a new way and created a business miracle in a saturated competition field that seems to have no chance. Since its establishment, Pinduoduo has been committed to poverty alleviation work, helping poor farmers in remote areas to connect with the consumer market, gathering massive demand in a short period of time, so as to help poor farmers solve the problem of unsalable agricultural products in the current season, and achieve effective income increase. The effect of poverty alleviation is remarkable. Pinduoduo constantly explores the mechanism of consumption poverty alleviation, and uses the innovative mode of consumption poverty alleviation to help poor areas to achieve self-poverty alleviation, wons the title of "China's excellent poverty alleviation cases". In the future, Pinduoduo will invest more human and material resources to continue to create more value for poor farmers and the broad consumer group. In recent years, under the guidance of the strategy thinking of targeted poverty alleviation, Pinduoduo has actively carried out poverty alleviation activities for farmers, continuously explored, innovated and practiced the mechanism of poverty alleviation for farmers, and successively launched "duoduoguoyuan", "duoduonongyuan" and other effective innovation modes for poverty alleviation. Based on Pinduoduo's consumption poverty alleviation, tens of thousands of ecommerce businesses in poverty-stricken areas have been supported. The group shopping mode of agricultural products launched by Pinduoduo has directly opened up a fast channel for decentralized agricultural products in remote areas to reach consumers, helps agricultural products to catch the ride of social commerce, and thus helps increase farmers's incomes.

Since 2018, Pinduoduo has continued to implement innovative industry poverty alleviation projects in poor areas such as Yunnan, Guizhou, and Xinjiang, and achieved remarkable results. For example, the hot sale of Yunnan snow lotus fruit is one of the famous cases of Pinduoduo helping farmers to alleviate poverty. With the help of Pinduoduo platform, they have never been noticed to now become super web celebrity. Due to its high output value and the excavated uses are mostly used for soup, the market demand of snow lotus fruit is small and there is a serious unsalable crisis, which has led to the abandonment of seeds in many places in Yunnan and the planting area has been greatly reduced. In response to this dilemma, Pinduoduo launched "duoduonongyuan" and through the "new agribusiness" mode, explored new uses of snow lotus fruit that can be used for weight loss and so on, so that it was warmly welcomed by consumers, once sold well, in recent years, popular in first and second tier cities. According to the statistics of 2018, with the help of group buying mode of Pinduoduo platform, more than 36 million jin of snow lotus fruit were sold, and the 
planting area exceeded 90,000 mu, bringing more than 80 million yuan incomes to poor areas of Yunnan. Another example is the unsalable situation of fragrant pears in Korla, Xinjiang, where local agricultural enterprises sell about 500 tons of fragrant pears in less than two months with the help of Pinduoduo platform. More consumption poverty alleviation cases of Pinduoduo, such as "yanlaoxier" Shanxi specialty shop, which promotes the local unsalable specialty -- Yellow River Beach Jujube by means of social group buying in Pinduoduo, quickly sells more than 2000 tons, and the huge sales volume successfully helps the jujube farmers in many counties to get rid of the difficulties. For another example, in April 2018, Zhongmou garlic in Henan province had a good harvest but was unsalable. With the help of Pinduoduo, 330000 Jin of "poverty alleviation garlic" were sold in just one day when the activity was launched, adding over one million yuan to the local poor households...... These successful cases of Pinduoduo consumption poverty alleviation show that the new e-commerce poverty alleviation mode based on the social commerce platform such as Pinduoduo for consumption poverty alleviation plays an important promoting role in solving the problem of poor sales of agricultural products and realizing consumption. It solves the problem of agricultural product sales upgrading faced by traditional e-commerce, so it can further prove that the emerging mode of social commerce consumption poverty alleviation is effective and feasible.

$5 \mathrm{G}$ is the fifth generation mobile communication technology after $4 \mathrm{G}$, which is gradually breaking the traditional means of communication. The continuous development of communication technology has brought great convenience to people's lives, greatly promoted the development of national economy and improved the level of informatization. The future-oriented 5G technology has become a research hotspot at home and abroad. 5G will bring huge impact to the e-commerce industry, especially to the social commerce centered on interpersonal interaction. 5G will bring greater development space to the social commerce platform. The application of 5G technology will further increase the speed of social networks and reduce traffic charges, which will allow more people to enter mobile social networks, bring new development opportunities to social commerce, and achieve explosive growth.

5G technology brings a wider range of network coverage, and its advantages such as high speed, low latency, and large capacity will achieve a wide range of connections between different things, making human society enter the era of real "interconnection of all things". 5G will full come into our life and work in the future. Therefore, in view of the future development prospect of 5G technology, this paper innovatively proposes to apply 5G technology to the mode of social commerce consumption poverty alleviation, in order to further help targeted poverty alleviation. Through 5G, you can get the big data you need, adjust crop production according to the data information you get, and improve the quality of agricultural products. At the same time, it can realize ultra-high-definition $4 \mathrm{~K}$ live broadcast under $5 \mathrm{G}$, so it can realize the direct contact between the poor areas and the outside world through the video live broadcast with clear picture and no jam. For example, Meitan County, Guizhou, has successfully used ultra-high-definition 4K live broadcast supported by $5 \mathrm{G}$ to allow online audiences to directly perceive the production status of tea gardens and talk to tea farmers in real time, which directly and effectively increases the influence of Guizhou tea brands. Therefore, the application of 5G technology will help the agricultural products in poor areas to improve product quality and brand influence, so as to promote online sales of agricultural products and realize consumption, and then promote the economic development of poor areas, and help targeted poverty alleviation. Therefore, the application of 5G technology will promote the innovation and improvement of the poverty alleviation mode and accelerate implementation of targeted poverty alleviation, that is, 5G technology will contribute to poverty alleviation. However, there are few studies on the application of 5G technology to targeted poverty alleviation, so this research is of great significance in theory and practice.

\section{Conclusion}

Since 2015, China clearly proposed to develop rural e-commerce, it has been five years in a row until 2019, it still continues to emphasize that e-commerce enters the countryside, and vigorously develops rural e-commerce. Rural e-commerce helps targeted poverty alleviation effectively 
accelerate the process of achieving rural revitalization. E-commerce poverty alleviation has become the current innovative poverty alleviation method. The effect of poverty alleviation depends on the selection and application of the poverty alleviation mode, so in order to better promote poverty alleviation, the poverty alleviation mode is constantly explored and innovated. Combined with the present situation and development conditions of poverty alleviation, this study creatively puts forward the mode of social commerce consumption poverty alleviation. The research analysis shows that the innovative mode of social commerce consumption poverty alleviation helps to promote the sale of agricultural products and stimulate consumption demand, thereby driving local economic development and achieving faster poverty alleviation, meanwhile, further improving the poverty alleviation mode. Therefore, this paper believes that the new mode of social commerce consumption poverty alleviation should be applied to poverty alleviation, so as to help speed up out of poverty and finally realize rural revitalization.

\section{References}

[1] Qiuju Mou. (2017) Analysis of e-commerce supporting targeted poverty alleviation in rural areas -- Taking Guizhou Province as an example. Agricultural economy, (07): 48-50.

[2] Shiwen Lei, Junxiao Yang, Fangjiang Deng, Xiaobo Yin. (2019) Research on rural e-commerce development in Xinjiang from the perspective of targeted poverty alleviation. Northeast Agricultural Science, 44 (03): 88-91.

[3] Xiangqin Song, Heng Du, Jun Zheng. (2018) Research on rural e-commerce poverty alleviation strategy based on SWOT analysis -- Taking Southeast Chongqing as an example. Agricultural economy, (06): 134-136.

[4] Li, L., Du, K., Zhang, W., \& Mao, J. Y. (2019) Poverty alleviation through government-led e-commerce development in rural China: An activity theory perspective. Information Systems Journal, 29(4), 914-952.

[5] Chao Tang, Mingzhong Luo. (2019) Characteristics and institutional constraints of e-commerce poverty alleviation mode in poor areas -- an example from Dangshan County, Anhui Province. Journal of northwest agricultural and Forestry University of science and Technology (SOCIAL SCIENCE EDITION), 19 (04): 96-104.

[6] Xiaohong Wang, Naxin Liu, Jing Zhang, Wu Tang. (2017) Analysis of poverty alleviation mode of "financial service station + Internet + rural e-commerce" -- Based on the practice of poverty alleviation in Yanling County of Hunan province. Wuhan finance, (11): 70-73.

[7] Chongyi Guo, Tingzhen Mi. (2019) E-commerce poverty alleviation in Longnan: mode, mechanism and countermeasures. Business economy research, (10): 80-82.

[8] Guoliang Dai. (2018) A study on pre purchase sharing motivation of social e-commerce. China's circulation economy, 32 (10): 39-47.

[9] Zixuan Huang. (2018) A comparative study of social e-commerce and traditional e-commerce -Taking Pinduoduo and Taobao as examples. Economic and trade practice, (23): 188-189.

[10] Gibreel, O., AlOtaibi, D. A., \& Altmann, J. (2018) Social commerce development in emerging markets. Electronic Commerce Research and Applications, 27, 152-162.

[11] Haili Ma. (2018) Analysis on the integration prospect of social network and e-commerce development. Business economy research, (08): 66-68.

[12] Xiaokui Jia. (2017) The development mode and market prospect of social e-commerce under the tide of "Internet +". business economics research, (22): 75-77.

[13] Chaoyang Lin. (2018) Profit dilemma and breakthrough of social e-commerce mode -- Taking mushroom street and Meilishuo as an example. Business economy research, (06): 70-72. 
[14] Qianheng Chen. (2019) Poverty alleviation through consumption: bridging urban and rural demand. People's forum, (23): 80-82.

[15] Yongmei Sun, Qing Fang. (2017) Poverty measurement and targeted poverty alleviation exploration from the perspective of consumption - based on the research of consumption poverty in rural areas of China. Teaching and research, (04): 23-32.

[16] Jingjie Chen. (2019) Realization path to poverty alleviation through consumption of commercial banks. China finance, (09): 55-56.

[17] Jianhua Ge. (2019) Research on the construction and operation of "one-stop" consumption poverty alleviation e-commerce platform. Guangdong Social Sciences, (03): 42-49.

[18] Shuhan Yang, Huixuan Fan. (2018) Research on the mode application and development status of social e-commerce in the era of mobile Internet -- Taking the social e-commerce in the wechat ecosystem as an example. Modern business industry, 39 (23): 80-82.

[19] Mamonov, S., \& Benbunan-Fich, R. (2017) Exploring factors affecting social e-commerce service adoption: The case of Facebook Gifts. International Journal of Information Management, 37(6), 590-600. 